\title{
Non-coding RNAs regulating morphine function: with emphasis on the in vivo and in vitro functions of miR-190
}

\author{
Hui Zheng ${ }^{1}$, Ping-Yee Law ${ }^{2}$ and Horace H. Loh ${ }^{2}$ \\ 'Key Laboratory of Regenerative Biology, South China Institute for Stem Cell Biology and Regenerative Medicine, Guangzhou Institutes of Biomedicine and Health, \\ Chinese Academy of Sciences, Guangzhou, China \\ 2 Department of Pharmacology, University of Minnesota, Minneapolis, MN, USA
}

\section{Edited by:}

Leonard Lipovich, Wayne State

University, USA

\section{Reviewed by:}

Yuichiro Watanabe, University of

Tokyo, Japan

Terrence Chi-Kong Lau, City University

of Hong Kong, Hong Kong

Ulf Andersson Ørom, Max Planck

Institute for Molecular Genetics,

Germany

\section{${ }^{*}$ Correspondence:}

Hui Zheng, Key Laboratory of

Regenerative Biology, South China Institute for Stem Cell Biology and

Regenerative Medicine, Guangzhou

Institutes of Biomedicine and Health,

Chinese Academy of Sciences, A-131,

190 Kaiyuan Avenue, Science City,

Guangzhou 510530, China.

e-mail: zheng_hui@gibh.ac.cn
Non-coding RNAs (ncRNAs), especially microRNAs, are reported to be involved in a variety of biological processes, including several processes related to drug addiction. It has been suggested that the biological functions of opioids, one typical type of addictive drugs, are regulated by ncRNAs. In the current review, we examine a variety of mechanisms through which ncRNAs could regulate $\mu$-opioid receptor (OPRM1) activities and thereby contribute to the development of opioid addiction. Using miR-23b as an example, we present the possible ways in which ncRNA-mediated regulation of OPRM1 expression could impact opioid addiction. Using miR-190 as an example, we demonstrate the critical roles played by ncRNAs in the signal cascade from receptor to systemic responses, including the possible modulation of adult neurogenesis and in vivo contextual memory. After discussing the possible targets of ncRNAs involved in the development of opioid addiction, we summarize the mechanisms underlying the interaction between ncRNAs and opioid addiction and present suggestions for further study.

Keywords: microRNA, miR-190, non-coding RNA, opioid addiction

\section{INTRODUCTION TO ncRNAs}

The central dogma - DNA transcription results in RNA production and RNA translation results in protein production - places RNA as an intermediate between gene and protein. It has been proposed that the information storage and catalytic functions of RNA have been transferred to DNA and protein, respectively, during evolution, however, the publication of the alanine tRNA structure in 1965 suggested that translation into protein was not the only function of an RNA molecule (Holley et al., 1965). Thus, noncoding RNA (ncRNAs, also named non-protein-coding RNA or non-messenger RNA) and mRNA are now considered to be two distinct parts of the RNA world.

For many years, tRNAs and rRNAs were the only known ncRNAs. However, more ncRNAs have been discovered recently, including small nuclear RNAs (snRNAs), small nucleolar RNAs (snoRNAs), microRNAs (miRNAs), piwi-interacting RNAs (piRNAs), small interfering RNAs (siRNAs), and long ncRNAs (Huttenhofer et al., 2005; Kurth and Mochizuki, 2009).

With the exception of long ncRNAs, ncRNAs are typically categorized by their function. For example, piRNAs form RNAprotein complexes with piwi proteins to induce epigenetic and post-transcriptional gene silencing in germ line cells (Girard et al., 2006). miRNAs bind to target mRNA via complementary sequences, usually resulting in translational repression or target degradation (Zeng and Cullen, 2003; Zeng, 2006; Bartel, 2009). Long ncRNAs are arbitrarily considered to be longer than 200 nucleotides. Although the functions of long ncRNAs require further investigation, they may function as signals, decoys, guides, or scaffolds (Kapranov et al., 2007; Mercer et al., 2009; Wang and Chang, 2011), and may be involved in drug addiction (Michelhaugh et al., 2011). In general, ncRNAs have been reported to affect multiple aspects of gene expression in a variety of biological processes (Shivdasani, 2006; Bueno et al., 2008; Ivey and Srivastava, 2010; Kaikkonen et al., 2011), including the development of several diseases, such as cancer, autism, Alzheimer's disease and drug addiction (Talebizadeh et al., 2008; Dreyer, 2010; Ferdin et al., 2010; Satoh, 2010). The current review discusses the involvement of ncRNAs in opioid addiction.

\section{INTRODUCTION TO OPIOID ADDICTION}

Alcohol, nicotine, caffeine, and opioids are the classic addictive drugs. Addiction to such drugs has been historically viewed from two aspects: (1) compulsive drug-taking and drug-seeking behavior is acquired because of the rewarding and reinforcement properties of the drug; and (2) drug withdrawal episodes enhance the drug's incentive value to such an extent that compulsive drugseeking and drug-taking takes over the behavioral repertoire. Although there are common pathways for drug addiction, the ability of these individual drugs to activate distinct signaling cascades and induce specific biological responses through binding to different receptors indicate that addiction to these drugs occurs through diverse mechanisms. In the current review, we focus on the probable influence of ncRNAs on opioid addiction (Nestler and Aghajanian, 1997). 
The history of opioid addiction can be traced back to the first use of morphine, one of the most efficacious and oldest drugs in the treatment of moderate to severe pain. There are also other opioids used in clinic or laboratory: fentanyl, oxycodone, etorphine, and [D-Ala ${ }^{2}, \mathrm{~N}-\mathrm{MePhe}^{4}$, Gly-ol]-enkephalin (DAMGO). Although opioid addiction is considered to be a complex process involving genetic/epigenetic, cellular, and molecular regulation of neuronal plasticity and drug-related contextual memory, opioid receptors are definitely the major determinants in the addiction process because the receptors are the initiation sites of all opioid function. Since the first discovery of the opioid receptor in 1973 by scientists (Pert and Snyder, 1973), four members in the family of opioid receptors have been identified: $\mu$ opioid receptor (OPRM1), $\delta$-opioid receptor (OPRD1), $\kappa$-opioid receptor (OPRK1), and nociceptin receptor (ORL1). OPRM1 and OPRM1-related pathways are discussed in the current review.

\section{OPIOID ADDICTION AND ncRNAs}

Although there has been no reported exploration of how ncRNAs regulate opioid addiction, several miRNAs have been suggested to interact with the signaling pathway downstream of OPRM1 and possibly be involved in the opioid addiction process, as reviewed by Dreyer and Li (Dreyer, 2010; Li and van der Vaart, 2011).

As summarized in Table 1 , by inducing a decrease in miR$133 \mathrm{~b}$ and a subsequent increase in the expression of Pitx3, morphine regulated dopaminergic neuron differentiation in zebra fish embryos (Sanchez-Simon et al., 2010). Significant changes in the expression of 26 miRNAs, including miR-15b and miR-181b, were identified between morphine-treated and control human monocyte-derived macrophages (Dave and Khalili, 2010). A let-7 binding site was identified in the $3^{\prime}$-UTR of OPRM1 mRNA, and decreasing the brain level of let-7 partially attenuated the tolerance induced by morphine (He et al., 2010). In the previous reports from our laboratory, long-term morphine treatment increased the expression of miR-20a, miR-23b, miR-224, miR-331, and miR-365 in both mice hippocampi and primary cultures of rat hippocampal neurons. Long-term fentanyl treatment increased the expression of miR-224, miR-331, and miR-365, but decreased the expression of miR-184, miR-190, and miR-301 (Wu et al., 2009; Zheng et al., 2010d). The agonist-selective regulation of miR-190 and its target, neurogenic differentiation 1 (NeuroD), resulted in differential influences over the dendritic spine stability of hippocampal neurons (Zheng et al., 2010c). In addition, miR-23b targeted the $3^{\prime}$-UTR of OPRM1 mRNA and regulated the association between OPRM1 mRNA and polysomes (Wu et al., 2008, 2009). Five long ncRNAs were up-regulated in the nucleus accumbens of heroin abusers when compared with drug-free control subjects (Michelhaugh et al., 2011). The ncRNAs listed in Table 1 may contribute to the development of opioid addiction by affecting different aspects of opioid signaling, though further confirmation is still required.

\section{ncRNAs MAY CONTRIBUTE TO OPIOID ADDICTION BY CONTROLLING RECEPTOR EXPRESSION}

On the one hand, opioid treatment affects the expression of several miRNAs: morphine treatment affected the expression levels of miR-23b and let-7, which have binding sites on the $3^{\prime}$-UTR of the OPRM1 mRNA and control the expression of OPRM1 (Wu et al., 2008, 2009; He et al., 2010). On the other hand, the expression level of opioid receptor, especially membrane receptor, is essential for receptor signaling or even opioid addiction. Some OPRM1 agonists, like etorphine and DAMGO, induce receptor internalization and subsequent loss of membrane receptor after acute treatment (El Kouhen et al., 2001; Eisinger and Schulz, 2005). Although debate still exists, receptor internalization correlates closely with signaling desensitization in vitro (Koch et al., 2001; Qiu et al., 2003) and analgesia tolerance in vivo (Zuo, 2005; Narita et al., 2006). In addition, OPRM1 down-regulation has been observed after chronic treatment with morphine (Davis et al., 1979) and has been considered as one mechanism for the development of opioid tolerance (Tao et al., 1987; Bhargava and Gulati, 1990). Since tolerance is linked with addiction, it is still reasonable to suggest the involvement of receptor down-regulation in opioid addiction. Thus, the signaling cascade from opioid to the expression of several

Table 1 | Non-coding RNAs involved in opioid signaling.

\begin{tabular}{|c|c|c|}
\hline ncRNAs involved & Phenomena & Reference \\
\hline let-7 & $\begin{array}{l}\text { Morphine increases the expression of let-7, which binds to the } 3^{\prime} \text {-UTR of OPRM1 } \\
\text { mRNA. Decreasing let-7 impaired morphine-induced tolerance }\end{array}$ & He et al. (2010) \\
\hline $\begin{array}{l}\text { miR-15b, miR-181b, plus } 24 \\
\text { additional miRNAs }\end{array}$ & $\begin{array}{l}\text { These } 26 \text { miRNAs were regulated in morphine-treated human monocyte-derived } \\
\text { macrophages }\end{array}$ & Dave and Khalili (2010) \\
\hline $\begin{array}{l}\text { miR-20a, miR-184, miR-224, } \\
\text { miR-301, miR-331, and } \\
\text { miR-365 }\end{array}$ & $\begin{array}{l}\text { Morphine increases the expression of miR-20a, miR-23b, miR-224, miR-331, and } \\
\text { miR-365. Fentanyl increases the expression of miR-224, miR-331, and miR-365, but } \\
\text { decreases the expression of miR-184, miR-190, and miR-301 }\end{array}$ & Zheng et al. (2010d) \\
\hline miR-23b & $\begin{array}{l}\text { Morphine increases the expression of miR-23b, which can regulate the expression } \\
\text { of OPRM1 }\end{array}$ & Wu et al. $(2008,2009)$ \\
\hline miR-133b & $\begin{array}{l}\text { Morphine decreases the expression of miR-133b in zebrafish embryos, which } \\
\text { subsequently affects dopaminergic neuron differentiation }\end{array}$ & Sanchez-Simon et al. (2010) \\
\hline miR-190 & $\begin{array}{l}\text { Fentanyl decreases the expression of miR-190, which subsequently affects the } \\
\text { NeuroD-related pathways }\end{array}$ & Zheng et al. (2010a,c,d) \\
\hline $\begin{array}{l}\text { MIAT, MEG3, NEAT1, NEAT2, } \\
\text { and EMX2OS }\end{array}$ & $\begin{array}{l}\text { These five long ncRNAs are up-regulated in the nucleus accumbens of heroin } \\
\text { abusers }\end{array}$ & Michelhaugh et al. (2011) \\
\hline
\end{tabular}


ncRNAs and then to OPRM1 expression may be a mechanism for opioid addiction.

There have been numerous studies of the promoter region and UTR of OPRM1 (Min et al., 1994; Kraus et al., 1995; Shigeta et al., 2008). Two miRNAs have been reported to bind the $3^{\prime}$-UTR of OPRM1 mRNA and regulate the expression of OPRM1. Let-7 bound to the 399-405 region in $3^{\prime}$-UTR of the human OPRM1 mRNA and the 402-408 region in the $3^{\prime}$-UTR of mouse OPRM1 mRNA. It also impaired the association between OPRM1 mRNA and polysomes (He et al., 2010). In our laboratory, the $\mathrm{K}$ box in the 3 '-UTR of the OPRM1 mRNA (3805-3812 bp downstream from the stop codon) was identified to be a negative cis-acting element (Wu et al., 2008). Since, in Drosophila, K box interacts with miR-2 and miR-16, which have seed sequences homologous to that of miR-23b (Kimura et al., 2004; Kokkola et al., 2005), we assessed the ability of miR-23b to regulate OPRM1 expression. Downregulation of miR-23b expression increased the endogenous level of OPRM1 protein in NS20Y cells (Wu et al., 2008). In order to determine the involvement of miR-23b in the signaling cascade of OPRM1, we also tested the expression of miR-23b after morphine treatment. Morphine treatment increased the expression of miR$23 \mathrm{~b}$ in an exogenous system (N2A cells stably expressing OPRM1) as well as an endogenous system (SHSY5Y and NMB cells; Wu et al., 2009). Although transcriptional regulation of OPRM1 mRNA is limited during opioid addiction since OPRM1 mRNA level does not change after morphine treatment (Brodsky et al., 1995), the post-transcriptional regulation of receptor expression should be studied in depth.

Let-7 and miR-23b are definitely not the only ncRNAs that regulate the expression of OPRM1. Additional ncRNAs can be identified via bioinformatics methods, microarray studies, or other experimental procedures. Basing future studies on the current understanding of ncRNAs, it will not be difficult to explore the mechanisms through which the identified ncRNAs regulate OPRM1 expression. However, it will be difficult to explore the roles played by these ncRNAs in opioid addiction. One of the most reasonable studies will be to determine whether opioid treatment can affect the expression of these miRNAs, as with the studies on let-7 and miR-23b.

\section{ncRNAs MAY CONTRIBUTE TO OPIOID ADDICTION VIA miR-190-RELATED PATHWAYS}

Addiction is highly related to changes in neuronal activity and involves a number of brain nuclei, thus, modulating neuronal circuitry should be one possible mechanism through which ncRNAs regulate opioid addiction (Di Chiara et al., 2004; Kelley, 2004; Koob, 2009). Since neuronal circuitry is a large and complex topic and ncRNAs can affect the expression of many proteins within the neuronal circuitry (Bartel, 2004; Kosik, 2006), the current discussion focuses on the signaling cascade surrounding miR-190.

Using microarray analysis, we determined the opioid-induced changes in the expression profiles of miRNAs in primary cultures of hippocampal neurons and in mice hippocampi (Zheng et al., 2010d). Two opioids, morphine and fentanyl, were used in our studies, because of their different characteristics in inducing receptor internalization, receptor phosphorylation, and receptor desensitization (Keith et al., 1996; Zhang et al., 1998; Chu et al., 2010;
Zheng et al., 2011). The two opioids induced similar changes in the expression of miR-224, miR-331, and miR-365, but had agonistselective effects on the expression of miR-20a, miR-184, miR-190, and miR-301 (Zheng et al., 2010d). In our several other reports, we delineated both the upstream and downstream signaling pathways of miR-190 (Zheng et al., 2010a,b,c, 2011).

The signaling cascades surrounding miR-190 are summarized in Figure 1. Fentanyl, but not morphine, uses the $\beta$-arrestin pathway to induce extracellular signal-regulated kinase (ERK) phosphorylation and leads to the nuclear translocation of phosphorylated ERK. Phosphorylated ERK decreases transcription of Talin 2 by affecting the phosphorylation status of Yin Yang 1 (YY1) and the subsequent interaction between YY1 and Talin2 promoter (Zheng et al., 2008, 2010a). Since miR-190 is located in the intron of Talin2, fentanyl treatment decreases the expression of miR-190. Since morphine induces ERK phosphorylation in a PKC-dependent manner, morphine treatment does not affect the expression of miR-190, an example of agonist-selective regulation on miR-190 expression.

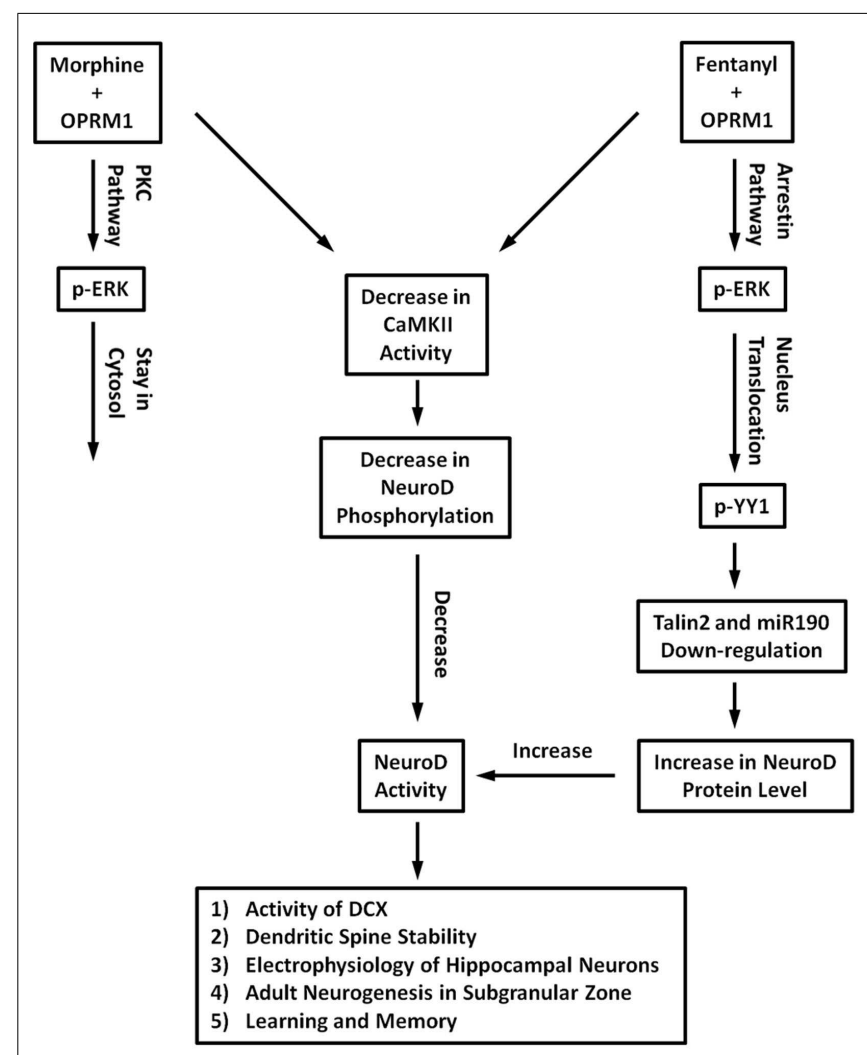

FIGURE 1 | Schematic illustration of signaling pathways surrounding miR-190. Morphine uses PKC pathway to induce ERK phosphorylation, fentanyl induces ERK phosphorylation in a $\beta$-arrestin-dependent manner. Fentanyl decreases miR-190 expression via $\beta$-arrestin pathway, YY1, and talin2. Fentanyl-increased NeuroD protein level was mediated by miR-190. Since both morphine and fentanyl impaired CaMKIl $\alpha$ activity, there is agonist-selective regulation on NeuroD activity. Morphine decreases NeuroD activity, but fentanyl keeps it at basal level. The activity of NeuroD may contribute to DCX expression, dendritic spine stability, neuron functions, adult neurogenesis, learning, and memory. 
miR-190 binds to the $3^{\prime}$-UTR of NeuroD mRNA and induces a decrease of NeuroD protein (Zheng et al., 2010d). NeuroD activity is influenced by both the NeuroD protein level and calcium/calmodulin-dependent protein kinase II $\alpha$ (CaMKII $\alpha)$ mediated phosphorylation on serine 336 (Gaudilliere et al., 2004). Since both morphine and fentanyl decrease the activity of CaMKII $\alpha$, the two opioids regulate NeuroD activity differentially (Zheng et al., 2010c). On the one hand, after fentanyl treatment, decreased expression of miR-190 leads to an increase in NeuroD protein, which counteracts the reduced activity of CaMKII $\alpha$. Thus, fentanyl maintains NeuroD activity close to basal levels. On the other hand, after morphine treatment, miR-190 expression is not affected, but the reduced activity of CaMKII $\alpha$ leads to the impaired activity of NeuroD. Thus, morphine decreases NeuroD activity (Zheng et al., 2010c).

Since NeuroD is critical for neuronal morphology (Gaudilliere et al., 2004), morphine and fentanyl differentially regulate dendritic spine stability and the electrophysiology of hippocampal neurons (Liao et al., 2007a,b; Zheng et al., 2010c). Furthermore, due to the involvement of NeuroD and its target, Doublecortin (DCX), in adult neurogenesis in the subgranular zone of dentate gyrus (Cho and Tsai, 2004; Hevner et al., 2006; von Bohlen Und Halbach, 2007), there may exist a connection between agonistselective signaling, opioid addiction, and ncRNA expression (Eisch and Harburg, 2006; Leuner et al., 2006).

To characterize the possible connection between miR-190related signaling pathways and opioid addiction, we categorized the factors mentioned above into three types: (1) those related to agonist-dependent signaling of OPRM1 including $\beta$-arrestin, ERK, and YY1; (2) those expressed in the central nervous system with close relation with miR-190, including CaMKII $\alpha$ and Talin2; and (3) NeuroD and NeuroD-related biological processes, including dendritic spine stability, adult neurogenesis, contextual learning, and memory.

\section{Agonist-selective signaling}

The first several factors discussed here are closely related to agonist-selective signaling. Different from the "intrinsic efficacy" concept, which suggests that each agonist activates the signaling pathways under one particular receptor with similar efficacies (Furchgott, 1966; Kenakin, 1995), agonist-selective signaling theory suggests that agonists may activate different signaling pathways differentially (Urban et al., 2007; Drake et al., 2008). Although no direct evidence links agonist-selective signaling with opioid addiction, the opioids do have differing abilities to induce tolerance (Duttaroy and Yoburn, 1995).

Extracellular signal-regulated kinase phosphorylation may be involved in opioid addiction. The ERK pathway has been reported to regulate learning and memory, which in turn relate to drug addiction (Mazzucchelli et al., 2002). In addition, addictive and non-addictive drugs induce distinct and specific patterns of ERK activation in the mouse brain (Valjent et al., 2004). The possible involvement of the ERK pathway in opioid addiction is further supported by the roles of ERK in opioid reward (Liu et al., 2007), opioid withdrawal (Asensio et al., 2006; Li et al., 2010), and opioidinduced conditioned place preference (Valjent et al., 2006; Lin et al., 2010).
Agonist-selective ERK phosphorylation may be involved in opioid addiction. Two pathways can be used by G proteincoupled receptors (GPCRs) to mediate ERK phosphorylation: the $\mathrm{PKC} / \mathrm{PKA}$ pathway and the $\beta$-arrestin pathway, as demonstrated by siRNA and kinase inhibitor studies (Shenoy et al., 2006; DeWire et al., 2007; Violin and Lefkowitz, 2007). The selectivity of agonists for these two pathways is indicated by the abilities of agonists to use the pathways to induce ERK phosphorylation (Azzi et al., 2003; Kohout et al., 2004; Shenoy et al., 2006). For OPRM1, morphine acts through the PKC pathway to induce ERK phosphorylation, and the phosphorylated ERK remains in the cytosol. Etorphine and fentanyl prefer to use the $\beta$-arrestin pathway to induce ERK phosphorylation, and the phosphorylated ERK translocates into nucleus (Zheng et al., 2008). Since the differences among opioids in inducing ERK phosphorylation are consistent with their differences in inducing receptor phosphorylation (Zhang et al., 1998; Zheng et al., 2010b, 2011), receptor internalization (Keith et al., 1996; Koch et al., 2005), and receptor desensitization (Johnson et al., 2006; Chu et al., 2008, 2010), agonist-selective ERK phosphorylation may be involved in opioid addiction.

How ERK phosphorylation and agonist-selective ERK phosphorylation contribute to opioid addiction is still unclear. Whether miR-190, which is downstream of ERK pathway, is involved is also not clear. However, miR-190 is not likely to be the only ncRNA whose expression is regulated by ERK pathway. In addition, it is likely that there additional ncRNAs that regulate the expression of ERK or related factors like PKC and $\beta$-arrestin. Thus, further investigation is required to define the connection between agonist-selective signaling and opioid addiction.

\section{Neuronal related factors}

The sequence of miR-190 is conserved between human, mouse, and rat, and is located in the intronic regions of the gene encoding Talin2 in each genome (Griffiths-Jones et al., 2008). Similar to other miRNAs located within the intronic regions (Rodriguez et al., 2004), the expression of miR-190 is regulated by Talin2 promoter activity, at least in part (Zheng et al., 2010d). Although Talin2 has not been well studied, its functions can be predicted by the reports on its homolog, Talin1. Talin 1 is considered to be an integrin-associated cytoskeletal protein and induces conformational changes in integrin that increase the affinity of its extracellular domains for ligand (Calderwood, 2004; Critchley, 2009). Talin 2 is similar in amino acid sequence to Talin 1 (74\% identity and $86 \%$ similarity). Talin 1 expression is highest in the heart and lowest in the brain, as measured in both mouse and human (Ben-Yosef and Francomano, 1999; Monkley et al., 2001). The Talin 2 expression pattern is different from that of Talin 1, with highest expression in heart and the second highest expression in brain (Monkley et al., 2001). Considering their sequence similarity and differential expression patterns, Talin2 may execute the function of Talin 1 in brain. Thus, the opioid-induced modulation of Talin2 transcription may affect cell adhesion to the extracellular matrix, which may subsequently influence neuronal circuitry and opioid addiction. These functions indicate that Talin 2 is a potential start for ncRNA-mediated regulation of opioid addiction.

CaMKII $\alpha$ activation is one of OPRM1's downstream signaling pathways (Lou et al., 1999). The activity of CaMKII $\alpha$ increases 
after acute morphine treatment, gradually returns to basal levels after chronic morphine treatment, and reaches to a high level if naloxone is used to precipitate the opiate withdrawal (Lou et al., 1999). As an important factor in central nervous system, CaMKII $\alpha$ is essential for synaptic transmission and dendritic morphology (Colbran and Brown, 2004), and its phosphorylation is associated with microtubule stabilization and dendrite formation (Vaillant et al., 2002; Okamoto et al., 2009). In addition, CaMKII $\alpha$ activation has been reported to be a mediator for the development of opioid tolerance (Fan et al., 1999; Shukla et al., 2006). The CAMKII $\alpha$ signaling pathway has been considered a common pathway for drug addiction (Steiner et al., 2007; Anderson et al., 2008; Li et al., 2008).

\section{NeuroD}

Neurogenic differentiation 1 is critical for the development of both the central nervous and endocrine systems. NeuroD null mice have difficulty surviving after birth without insulin supplement. Surviving mice have defects in the cerebella and hippocampi (Cho and Tsai, 2004). NeuroD is an important transcription factor during adult neurogenesis in the subgranular zone of the hippocampus (von Bohlen Und Halbach, 2007), and is expressed at high levels during the differentiation and migration of neuronal stem cells. In addition to supporting the formation of new neuronal circuitry, NeuroD also contributes to the stability of existing circuitry. CaMKII $\alpha$-mediated NeuroD phosphorylation supports the formation and maintenance of dendritic morphology in cerebellar granule neurons (Gaudilliere et al., 2004). Reducing NeuroD activity with miR-190 or CaMKII $\alpha$ inhibitors impairs the stability of dendritic spines in hippocampal neurons (Zheng et al., 2010c). Therefore, by regulating the neuronal circuitry, NeuroD may contribute to opioid addiction.

In addition to NeuroD itself, its target doublecortin (DCX) is also a critical factor in adult neurogenesis (Seo et al., 2007; von Bohlen Und Halbach, 2007). Since addictive drugs such as alcohol, morphine, and cocaine regulate adult neurogenesis in the hippocampus (Eisch et al., 2000; Nixon, 2006; Noonan et al., 2010), a connection between adult neurogenesis and drug addiction has been suggested (Eisch and Harburg, 2006; Canales, 2007). This hypothesis is supported by studies on learning and memory which are connected to both neurogenesis (Leuner et al., 2006; Deng et al., 2010) and drug addiction (Davis and Gould, 2008; Robbins et al., 2008). In addition, miR-19b and miR-124 have been reported to target NeuroD (Liu et al., 2011; Zhang et al., 2011), thus, these two ncRNAs may regulate opioid addiction by affecting NeuroD-related pathways.

\section{ncRNAs MAY CONTRIBUTE TO OPIOID ADDICTION BY AFFECTING OTHER BIOLOGICAL PROCESSES}

Above we discuss how factors related to miR-190 may contribute to opioid addiction. Other miRNAs, including miR-133b and let-7, will be described in depth in other reviews in this issue. However, not all miRNAs identified in the published reports have been well studied. For example, 24 miRNAs, in addition to miR$15 \mathrm{~b}$ and miR-181b, were identified in a comparison of miRNA expression in morphine-treated versus control samples (Dave and Khalili, 2010). We also identified several miRNAs whose expression changed significantly after morphine or fentanyl treatment in primary hippocampal cultures and mouse brain (Zheng et al., 2010d). Although the majority of these miRNAs relate to cell proliferation or cancer development, it was demonstrated that several miRNAs are involved in opioid addiction.

For example, miR-26b targets the $3^{\prime}$-UTR of brain-derived neurotrophic factor (BDNF) mRNA (Caputo et al., 2011). BDNF is a neurotrophin that is an essential part of neuronal development and plasticity (Greenberg et al., 2009). A study on alcohol and cocaine also demonstrated BDNF's central role in drug addiction (Janak et al., 2006; McGinty et al., 2010). The expression of miR132 in neuronal cultures is up-regulated by BDNF (Numakawa et al., 2011), and miR-132 mediates the regulation of BDNF on glutamate receptors (Kawashima et al., 2010). Other studies have revealed the interaction between miR-132 and other addictionrelated pathways, including CREB and ERK signaling cascades (Remenyi et al., 2010), dendritic spine morphology and synaptic physiology (Edbauer et al., 2010; Mellios et al., 2011), and the integration of newborn neurons into the adult dentate gyrus (Luikart et al., 2011). miR-301 affects the ERK and CREB pathways by targeting EMOX2 (Cao et al., 2010).

\section{SUMMARY}

To further explore the possible mechanisms through which ncRNAs contribute to opioid addiction, a simplified schematic illustration is provided in Figure 2. The binding of an opioid to OPRM1 leads to various biological responses, some of which ultimately lead to addiction. The ncRNAs involved in opioid addiction can be classified into two categories: (1) ncRNAs whose expression are regulated by opioids and mediate one or several biological responses that lead to addiction, and (2) ncRNAs whose expression are not regulated by opioids, but support the cascade from receptor to biological responses and then to addiction. The ncRNAs listed in Table 1 should belong to the first category if their contribution to opioid addiction is confirmed in future investigations, since not all ncRNAs regulated by opioids contribute to the development of addiction. The number of ncRNAs in the second category can be larger than those in the first, since the development of opioid addiction requires a large number of biological steps. Unfortunately, reports on these ncRNAs are limited, possibly because they are not regulated by opioids and thus have relatively lower significance in this field.

In further studies of the relationship between ncRNAs and opioid addiction, the key point will be to confirm the involvement of ncRNAs in the development of opioid addiction. One common method for confirmation is monitoring the development of opioid addiction after modulating the expression of a specific ncRNA. The categorization of ncRNAs mentioned above will be also useful when using the involved ncRNAs as targets to control the development of opioid addiction. Counteracting opioid-induced changes in the expression of ncRNAs in category 1 may lead to fewer side effects than blocking opioid tolerance by modulating the expression of ncRNAs in category 2.

As mentioned above, most functions of ncRNAs target different aspects of gene expression, thus, controlling the expression of essential factors in opioid signaling cascades or neuronal circuitry is one of the most likely mechanisms for regulation of opioid addiction by ncRNAs. In the sections above, we discussed several 


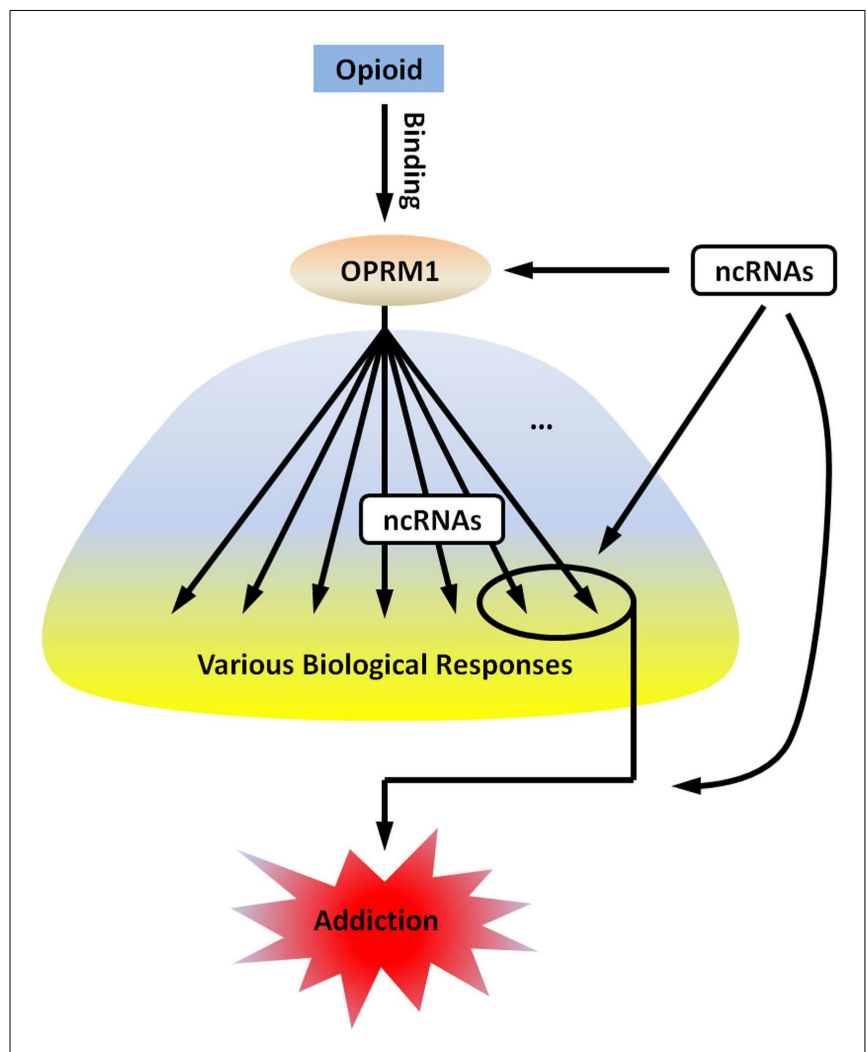

FIGURE 2 |The possible mechanisms through which ncRNAs contribute to opioid addiction. The binding of an opioid to OPRM1 leads to various biological responses, some of which ultimately lead to addiction. The ncRNAs involved in opioid addiction can be classified into two categories: (1) ncRNAs whose expression are regulated by opioids and mediate one or several biological responses that lead to addiction; and (2) ncRNAs whose expression are not regulated by opioids, but support the cascade from receptor to biological responses and then to addiction.

like down-regulation of the very low lipoprotein receptor and activation of TGF $\beta 1 / \mathrm{Smad} 3$ signaling pathway, may also influence opioid addiction (Ouda et al., 2011; Yuan et al., 2011).

Because of the multiple targets that may be impacted by a single ncRNA, as well as the complex and interrelated regulation of ncRNAs and their targets, it is difficult to identify the actual physiological role that each ncRNA exhibits in drug addiction processes. However, our studies of miR-190, which was identified in microarray analyses rather than bioinformatics, and the central transcription factor it regulates, NeuroD, will reveal interesting aspects of the role of ncRNAs in drug addiction.

By no means is miR-190-mediated regulation of NeuroD activities the definitive "the" physiological function of this miRNA. Rather, its activities will depend on the state of the neuronal cells in which it is expressed. For example, in addition to NeuroD, miR-190 can interact with other transcription factors that regulate neurogenesis, such as Pax6 (Zheng et al., 2010d). Pax6 expression is high in neural progenitor cells but low in differentiated neurons (BelVialar et al., 2007; Kallur et al., 2008). Therefore, one can imagine that an addictive drug such as morphine, by regulating a single ncRNA level such as miR-190, will have differential effects on cellular response, whether it is proliferation or differentiation, and will be dependent on the network of transcripts being expressed during the drug treatment.

Furthermore, because ncRNAs are end products of transcript maturation, one expects that different neurons, different neural circuitry, and different brain regions will exhibit differential regulation of ncRNAs by the same addictive drugs. Such complex patterns of ncRNA regulation could have significant impact on the overall responses to addictive drugs. Our study on miR-190 regulation of NeuroD activities leading to dendritic morphology changes is only the beginning of a very complex and elaborate process by which addictive drugs such as morphine could alter neural activities and, eventually, behavioral outcome.

\section{ACKNOWLEDGMENTS}

This research was supported by the "National Natural Science Foundation of China (31100773)," the "Strategic Priority Research Program" of the Chinese Academy of Sciences (XDA01020302), and the "Major New Drugs Innovation" of the Major National Scientific and Technological Project (2011ZX09102-010-01). The research was also supported by NIH grants DA023905 and DA011806.

mechanism, and function. Cell 116, 281-297.

Bartel, D. P. (2009). MicroRNAs: target recognition and regulatory functions. Cell 136, 215-233.

Bel-Vialar, S., Medevielle, F., and Pituello, F. (2007). The on/off of Pax6 controls the tempo of neuronal differentiation in the developing spinal cord. Dev. Biol. 305, 659-673.

Ben-Yosef, T., and Francomano, C. A. (1999). Characterization of the human talin (TLN) gene: genomic structure, chromosomal localization, and expression pattern. Genomics 62, 316-319.

Bhargava, H. N., and Gulati, A. (1990). Down-regulation of brain and spinal cord mu-opiate receptors in morphine tolerant-dependent rats. Eur. J. Pharmacol. 190, 305-311.

Brodsky, M., Elliott, K., Hynansky, A., and Inturrisi, C. E. (1995). CNS levels of mu opioid receptor (MOR1) mRNA during chronic treatment with morphine or naltrexone. Brain Res. Bull. 38, 135-141. 
Bueno, M. J., Perez De Castro, I., and Malumbres, M. (2008). Control of cell proliferation pathways by microRNAs. Cell Cycle 7, 3143-3148.

Calderwood, D. A. (2004). Talin controls integrin activation. Biochem. Soc. Trans. 32, 434-437.

Canales, J. J. (2007). Adult neurogenesis and the memories of drug addiction. Eur. Arch. Psychiatry Clin. Neurosci. 257, 261-270.

Cao, G., Huang, B., Liu, Z., Zhang, J., Xu, H., Xia, W., Li, J., Li, S., Chen, L., Ding, H., Zhao, Q., Fan, M., Shen, B., and Shao, N. (2010). Intronic miR-301 feedback regulates its host gene, ska2, in A549 cells by targeting MEOX2 to affect ERK/CREB pathways. Biochem. Biophys. Res. Commun. 396, 978-982.

Caputo, V., Sinibaldi, L., Fiorentino, A., Parisi, C., Catalanotto, C., Pasini, A., Cogoni, C., and Pizzuti, A. (2011). Brain derived neurotrophic factor (BDNF) expression is regulated by microRNAs miR-26a and miR-26b allele-specific binding. PLoS ONE 6, e28656. doi:10.1371/journal.pone.0028656

Cho, J. H., and Tsai, M. J. (2004). The role of BETA2/NeuroD1 in the development of the nervous system. Mol. Neurobiol. 30, 35-47.

Chu, J., Zheng, H., Loh, H. H., and Law, P. Y. (2008). Morphine-induced mu-opioid receptor rapid desensitization is independent of receptor phosphorylation and beta-arrestins. Cell. Signal. 20, 1616-1624.

Chu, J., Zheng, H., Zhang, Y., Loh, H. H., and Law, P. Y. (2010). Agonistdependent mu-opioid receptor signaling can lead to heterologous desensitization. Cell. Signal. 22, 684-696.

Colbran, R. J., and Brown, A. M. (2004). Calcium/calmodulin-dependent protein kinase II and synaptic plasticity. Curr. Opin. Neurobiol. 14, 318-327.

Critchley, D. R. (2009). Biochemical and structural properties of the integrinassociated cytoskeletal protein talin. Annu. Rev. Biophys. 38, 235-254.

Dave, R. S., and Khalili, K. (2010). Morphine treatment of human monocyte-derived macrophages induces differential miRNA and protein expression: impact on inflammation and oxidative stress in the central nervous system. J. Cell. Biochem. 110, 834-845.

Davis, J. A., and Gould, T. J. (2008). Associative learning, the hippocampus, and nicotine addiction. Curr. Drug Abuse Rev. 1, 9-19.

Davis, M. E., Akera, T., and Brody, T. M. (1979). Reduction of opiate binding to brainstem slices associated with the development of tolerance to morphine in rats. J. Pharmacol. Exp. Ther. 211, 112-119.

Deng, W., Aimone, J. B., and Gage, F. H. (2010). New neurons and new memories: how does adult hippocampal neurogenesis affect learning and memory? Nat. Rev. Neurosci. 11, 339-350.

DeWire, S. M., Ahn, S., Lefkowitz, R. J., and Shenoy, S. K. (2007). Betaarrestins and cell signaling. Annu. Rev. Physiol. 69, 483-510.

Di Chiara, G., Bassareo, V., Fenu, S., De Luca, M. A., Spina, L., Cadoni, C., Acquas, E., Carboni, E., Valentini, V., and Lecca, D. (2004). Dopamine and drug addiction: the nucleus accumbens shell connection. Neuropharmacology 47(Suppl. 1), 227-241.

Drake, M. T., Violin, J. D., Whalen, E. J., Wisler, J. W., Shenoy, S. K., and Lefkowitz, R. J. (2008). beta-arrestin-biased agonism at the beta2-adrenergic receptor. J. Biol. Chem. 283, 5669-5676.

Dreyer, J. L. (2010). New insights into the roles of microRNAs in drug addiction and neuroplasticity. Genome Med. 2, 92.

Duttaroy, A., and Yoburn, B. C. (1995). The effect of intrinsic efficacy on opioid tolerance. Anesthesiology 82, 1226-1236.

Edbauer, D., Neilson, J. R., Foster, K. A., Wang, C. F., Seeburg, D. P., Batterton, M. N., Tada, T., Dolan, B. M., Sharp, P. A., and Sheng, M. (2010). Regulation of synaptic structure and function by FMRP-associated microRNAs miR-125b and miR-132. Neuron $65,373-384$.

Eisch, A. J., Barrot, M., Schad, C. A., Self, D. W., and Nestler, E. J. (2000). Opiates inhibit neurogenesis in the adult rat hippocampus. Proc. Natl. Acad. Sci. U.S.A. 97, 7579-7584.

Eisch, A. J., and Harburg, G. C. (2006). Opiates, psychostimulants, and adult hippocampal neurogenesis: insights for addiction and stem cell biology. Hippocampus 16, 271-286.

Eisinger, D. A., and Schulz, R. (2005). Mechanism and consequences of delta-opioid receptor internalization. Crit. Rev. Neurobiol. 17, 1-26.

El Kouhen, R., Burd, A. L., EricksonHerbrandson, L. J., Chang, C. Y., Law, P. Y., and Loh, H. H. (2001). Phosphorylation of Ser363, Thr370, and Ser 375 residues within the carboxyl tail differentially regulates muopioid receptor internalization. J. Biol. Chem. 276, 12774-12780.

Fan, G. H., Wang, L. Z., Qiu, H. C., Ma, L., and Pei, G. (1999).
Inhibition of calcium/calmodulindependent protein kinase II in rat hippocampus attenuates morphine tolerance and dependence. Mol. Pharmacol. 56, 39-45

Ferdin, J., Kunej, T., and Calin, G. A. (2010). Non-coding RNAs: identification of cancer-associated microRNAs by gene profiling. Technol. Cancer Res. Treat. 9, 123-138.

Furchgott, R. (1966). The use of haloalkylamines in the differentiation of receptors and in the determination of dissociation of receptoragonist complexes. Adv. Drug Res. 3, 21-55.

Gaudilliere, B., Konishi, Y., de la Iglesia, N., Yao, G., and Bonni, A. (2004). A CaMKII-NeuroD signaling pathway specifies dendritic morphogenesis. Neuron 41, 229-241.

Girard, A., Sachidanandam, R., Hannon, G. J., and Carmell, M. A. (2006). A germline-specific class of small RNAs binds mammalian Piwi proteins. Nature 442, 199-202.

Greenberg, M. E., Xu, B., Lu, B. and Hempstead, B. L. (2009). New insights in the biology of BDNF synthesis and release: implications in CNS function. J. Neurosci. 29, 12764-12767.

Griffiths-Jones, S., Saini, H. K. van Dongen, S., and Enright, A. J. (2008). miRBase: tools for microRNA genomics. Nucleic Acids Res. 36, D154-D158.

He, Y., Yang, C., Kirkmire, C. M., and Wang, Z. J. (2010). Regulation of opioid tolerance by let7 family microRNA targeting the mu opioid receptor. J. Neurosci. 30, 10251-10258.

Hevner, R. F., Hodge, R. D., Daza, R. A., and Englund, C. (2006). Transcription factors in glutamatergic neurogenesis: conserved programs in neocortex, cerebellum, and adult hippocampus. Neurosci. Res. 55, 223-233.

Holley, R. W., Apgar, J., Everett, G. A., Madison, J. T., Marquisee, M., Merrill, S. H., Penswick, J. R., and Zamir, A. (1965). Structure of a ribonucleic acid. Science 147, 1462-1465.

Huttenhofer, A., Schattner, P., and Polacek, N. (2005). Non-coding RNAs: hope or hype? Trends Genet. 21, 289-297.

Ivey, K. N., and Srivastava, D. (2010). MicroRNAs as regulators of differentiation and cell fate decisions. Cell Stem Cell 7, 36-41.

Janak, P. H., Wolf, F. W., Heberlein, U., Pandey, S. C., Logrip, M. L., and Ron, D. (2006). BIG news in alcohol addiction: new findings on growth factor pathways BDNF, insulin, and
GDNF. Alcohol. Clin. Exp. Res. 30, 214-221.

Johnson, E. A., Oldfield, S., Braksator, E., Gonzalez-Cuello, A., Couch, D., Hall, K. J., Mundell, S. J., Bailey, C. P., Kelly, E., and Henderson, G. (2006). Agonist-selective mechanisms of mu-opioid receptor desensitization in human embryonic kidney 293 cells. Mol. Pharmacol. 70, 676-685.

Kaikkonen, M. U., Lam, M. T., and Glass, C. K. (2011). Non-coding RNAs as regulators of gene expression and epigenetics. Cardiovasc. Res. 90, 430-440.

Kallur, T., Gisler, R., Lindvall, O., and Kokaia, Z. (2008). Pax6 promotes neurogenesis in human neural stem cells. Mol. Cell. Neurosci. 38, 616-628.

Kapranov, P., Cheng, J., Dike, S., Nix, D. A., Duttagupta, R., Willingham, A. T., Stadler, P. F., Hertel, J., Hackermuller, J., Hofacker, I. L., Bell, I., Cheung, E., Drenkow, J., Dumais, E., Patel, S., Helt, G., Ganesh, M., Ghosh, S., Piccolboni, A., Sementchenko, V., Tammana, H., and Gingeras, T. R. (2007). RNA maps reveal new RNA classes and a possible function for pervasive transcription. Science 316, 1484-1488.

Kawashima, H., Numakawa, T., Kumamaru, E., Adachi, N., Mizuno, H., Ninomiya, M., Kunugi, H., and Hashido, K. (2010). Glucocorticoid attenuates brain-derived neurotrophic factor-dependent upregulation of glutamate receptors via the suppression of microRNA132 expression. Neuroscience 165, 1301-1311.

Keith, D. E., Murray, S. R., Zaki, P. A., Chu, P. C., Lissin, D. V., Kang, L., Evans, C. J., and Von Zastrow, M. (1996). Morphine activates opioid receptors without causing their rapid internalization. J. Biol. Chem. 271, 19021-19024.

Kelley, A. E. (2004). Memory and addiction: shared neural circuitry and molecular mechanisms. Neuron 44, 161-179.

Kenakin, T. (1995). Agonist-receptor efficacy I: mechanisms of efficacy and receptor promiscuity. Trends Pharmacol. Sci. 16, 188-192.

Kimura, H., Kawasaki, H., and Taira, K. (2004). Mouse microRNA-23b regulates expression of Hes1 gene in P19 cells. Nucleic Acids Symp. Ser. (Oxf.) 213-214.

Koch, T., Schulz, S., Pfeiffer, M., Klutzny, M., Schroder, H., Kahl, E., and Hollt, V. (2001). C-terminal splice variants of the mouse mu-opioid receptor differ in morphine-induced 
internalization and receptor resensitization. J. Biol. Chem. 276, 31408-31414.

Koch, T., Widera, A., Bartzsch, K., Schulz, S., Brandenburg, L. O., Wundrack, N., Beyer, A., Grecksch, G., and Hollt, V. (2005). Receptor endocytosis counteracts the development of opioid tolerance. Mol. Pharmacol. 67, 280-287.

Kohout, T. A., Nicholas, S. L., Perry, S. J., Reinhart, G., Junger, S., and Struthers, R. S. (2004). Differential desensitization, receptor phosphorylation, beta-arrestin recruitment, and ERK1/2 activation by the two endogenous ligands for the CC chemokine receptor 7. J. Biol. Chem. 279, 23214-23222.

Kokkola, T., Salo, O. M., Poso, A., and Laitinen, J. T. (2005). The functional role of cysteines adjacent to the NRY motif of the human MT1 melatonin receptor. J. Pineal Res. 39, 1-11.

Koob, G. F. (2009). Brain stress systems in the amygdala and addiction. Brain Res. 1293, 61-75.

Kosik, K. S. (2006). The neuronal microRNA system. Nat. Rev. Neurosci. 7, 911-920.

Kraus, J., Horn, G., Zimprich, A., Simon, T., Mayer, P., and Hollt, V. (1995). Molecular cloning and functional analysis of the rat mu opioid receptor gene promoter. Biochem. Biophys. Res. Commun. 215, 591-597.

Kurth, H. M., and Mochizuki, K. (2009). Non-coding RNA: a bridge between small RNA and DNA. RNA Biol. 6, 138-140.

Leuner, B., Gould, E., and Shors, T. J. (2006). Is there a link between adult neurogenesis and learning? Hippocampus 16, 216-224.

Li, C. Y., Mao, X., and Wei, L. (2008). Genes and (common) pathways underlying drug addiction. PLoS Comput. Biol. 4, e2. doi:10.1371/journal.pcbi.0040002

Li, M. D., and van der Vaart, A. D. (2011). MicroRNAs in addiction: adaptation's middlemen? Mol. Psychiatry 16, 1159-1168.

Li, T., Hou, Y., Cao, W., Yan, C. X., Chen, T., and Li, S. B. (2010). Naloxone-precipitated withdrawal enhances ERK phosphorylation in prefrontal association cortex and accumbens nucleus of morphinedependent mice. Neurosci. Lett. 468, 348-352.

Liao, D., Grigoriants, O. O., Loh, H. H., and Law, P. Y. (2007a). Agonistdependent postsynaptic effects of opioids on miniature excitatory postsynaptic currents in cultured hippocampal neurons. J. Neurophysiol. 97, 1485-1494.
Liao, D., Grigoriants, O. O., Wang, W., Wiens, K., Loh, H. H., and Law, P. Y. (2007b). Distinct effects of individual opioids on the morphology of spines depend upon the internalization of mu opioid receptors. Mol. Cell. Neurosci. 35, 456-469.

Lin, X., Wang, Q., Ji, J., and Yu, L. C. (2010). Role of MEK-ERK pathway in morphine-induced conditioned place preference in ventral tegmental area of rats. J. Neurosci. Res. 88, 1595-1604.

Liu, K., Liu, Y., Mo, W., Qiu, R., Wang, X., Wu, J. Y., and He, R. (2011). MiR124 regulates early neurogenesis in the optic vesicle and forebrain, targeting NeuroD1. Nucleic Acids Res. 39, 2869-2879.

Liu, Y., Wang, Y., Jiang, Z., Wan, C., Zhou, W., and Wang, Z. (2007). The extracellular signal-regulated kinase signaling pathway is involved in the modulation of morphine-induced reward by mPer1. Neuroscience 146 , 265-271.

Lou, L., Zhou, T., Wang, P., and Pei, G. (1999). Modulation of Ca2+/calmodulin-dependent protein kinase II activity by acute and chronic morphine administration in rat hippocampus: differential regulation of alpha and beta isoforms. Mol. Pharmacol. 55, 557-563.

Luikart, B. W., Bensen, A. L., Washburn, E. K., Perederiy, J. V., Su, K. G., Li, Y., Kernie, S. G., Parada, L. F., and Westbrook, G. L. (2011). miR132 mediates the integration of newborn neurons into the adult dentate gyrus. PLOS ONE 6, e19077. doi:10.1371/journal.pone.0019077

Mazzucchelli, C., Vantaggiato, C., Ciamei, A., Fasano, S., Pakhotin, P., Krezel, W., Welzl, H., Wolfer, D. P., Pages, G., Valverde, O., Marowsky, A., Porrazzo, A., Orban, P. C., Maldonado, R., Ehrengruber, M. U., Cestari, V., Lipp, H. P., Chapman, P. F., Pouyssegur, J., and Brambilla, R. (2002). Knockout of ERK1 MAP kinase enhances synaptic plasticity in the striatum and facilitates striatal-mediated learning and memory. Neuron 34, 807-820.

McGinty, J. F., Whitfield, T. W. Jr., and Berglind, W. J. (2010). Brainderived neurotrophic factor and cocaine addiction. Brain Res. 1314, 183-193.

Mellios, N., Sugihara, H., Castro, J., Banerjee, A., Le, C., Kumar, A., Crawford, B., Strathmann, J., Tropea, D., Levine, S. S., Edbauer, D., and Sur, M. (2011). miR-132, an experiencedependent microRNA, is essential for visual cortex plasticity. $\mathrm{Nat}$. Neurosci. 14, 1240-1242.
Mercer, T. R., Dinger, M. E., and Mattick, J. S. (2009). Long non-coding RNAs: insights into functions. Nat. Rev. Genet. 10, 155-159.

Michelhaugh, S. K., Lipovich, L., Blythe, J., Jia, H., Kapatos, G., and Bannon, M. J. (2011). Mining affymetrix microarray data for long noncoding RNAs: altered expression in the nucleus accumbens of heroin abusers. J. Neurochem. 116, 459-466.

Min, B. H., Augustin, L. B., Felsheim R. F., Fuchs, J. A., and Loh, H. H. (1994). Genomic structure analysis of promoter sequence of a mouse mu opioid receptor gene. Proc. Natl. Acad. Sci. U.S.A. 91, 9081-9085.

Monkley, S. J., Pritchard, C. A., and Critchley, D. R. (2001). Analysis of the mammalian talin2 gene TLN2. Biochem. Biophys. Res. Commun. 286, 880-885.

Narita, M., Suzuki, M., Narita, M., Niikura, K., Nakamura, A., Miyatake, M., Yajima, Y., and Suzuki, T. (2006). mu-Opioid receptor internalization-dependent and -independent mechanisms of the development of tolerance to mu-opioid receptor agonists: comparison between etorphine and morphine. Neuroscience 138, 609-619.

Nestler, E. J., and Aghajanian, G. K. (1997). Molecular and cellular basis of addiction. Science 278, 58-63.

Nixon, K. (2006). Alcohol and adult neurogenesis: roles in neurodegeneration and recovery in chronic alcoholism. Hippocampus 16, 287-295.

Noonan, M. A., Bulin, S. E., Fuller, D. C., and Eisch, A. J. (2010). Reduction of adult hippocampal neurogenesis confers vulnerability in an animal model of cocaine addiction. J. Neurosci. 30, 304-315.

Numakawa, T., Yamamoto, N., Chiba, S. Richards, M., Ooshima, Y., Kishi, S., Hashido, K., Adachi, N., and Kunugi, H. (2011). Growth factors stimulate expression of neuronal and glial miR-132. Neurosci. Lett. 505, 242-247.

Okamoto, K., Bosch, M., and Hayashi, Y. (2009). The roles of CaMKII and F-actin in the structural plasticity of dendritic spines: a potential molecular identity of a synaptic tag? Physiology (Bethesda) 24, 357-366.

Ouda, R., Onomoto, K., Takahasi, K., Edwards, M. R., Kato, H. Yoneyama, M., and Fujita, T. (2011). Retinoic acid-inducible gene Iinducible miR-23b inhibits infections by minor group rhinoviruses through down-regulation of the very low density lipoprotein receptor. $J$. Biol. Chem. 286, 26210-26219.
Pert, C. B., and Snyder, S. H. (1973). Opiate receptor: demonstration in nervous tissue. Science 179, 1011-1014.

Qiu, Y., Law, P. Y., and Loh, H. H. (2003). $\mathrm{Mu}$-opioid receptor desensitization: role of receptor phosphorylation, internalization, and representation. J. Biol. Chem. 278, 36733-36739.

Remenyi, J., Hunter, C. J., Cole, C., Ando, H., Impey, S., Monk, C. E., Martin, K. J., Barton, G. J., Hutvagner, G., and Arthur, J. S. (2010). Regulation of the miR-212/132 locus by MSK1 and CREB in response to neurotrophins. Biochem. J. 428, 281-291.

Robbins, T. W., Ersche, K. D., and Everitt, B. J. (2008). Drug addiction and the memory systems of the brain. Ann. N. Y. Acad. Sci. 1141, $1-21$.

Rodriguez, A., Griffiths-Jones, S., Ashurst, J. L., and Bradley, A. (2004). Identification of mammalian microRNA host genes and transcription units. Genome Res. 14, 1902-1910.

Sanchez-Simon, F. M., Zhang, X. X., Loh, H. H., Law, P. Y., and Rodriguez, R. E. (2010). Morphine regulates dopaminergic neuron differentiation via miR-133b. Mol. Pharmacol. 78, 935-942.

Satoh, J. (2010). MicroRNAs and their therapeutic potential for human diseases: aberrant microRNA expression in Alzheimer's disease brains. $J$. Pharmacol. Sci. 114, 269-275.

Seo, S., Lim, J. W., Yellajoshyula, D., Chang, L. W., and Kroll, K. L. (2007). Neurogenin and NeuroD direct transcriptional targets and their regulatory enhancers. $E M B O J$. 26, 5093-5108.

Shenoy, S. K., Drake, M. T., Nelson, C. D., Houtz, D. A., Xiao, K., Madabushi, S., Reiter, E., Premont, R. T., Lichtarge, O., and Lefkowitz, R. J. (2006). beta-arrestin-dependent, $\mathrm{G}$ protein-independent ERK1/2 activation by the beta 2 adrenergic receptor. J. Biol. Chem. 281, 1261-1273.

Shigeta, Y., Kasai, S., Han, W., Hata, H., Nishi, A., Takamatsu, Y., Hagino, Y., Yamamoto, H., Koide, T., Shiroishi, T., Kasai, K., Tsunashima, K., Kato, N., and Ikeda, K. (2008). Association of morphine-induced antinociception with variations in the $5^{\prime}$ flanking and $3^{\prime}$ untranslated regions of the mu opioid receptor gene in 10 inbred mouse strains. Pharmacogenet. Genomics 18, 927-936.

Shivdasani, R. A. (2006). MicroRNAs: regulators of gene expression and cell differentiation. Blood 108, 3646-3653. 
Shukla, P. K., Tang, L., and Wang, Z. J. (2006). Phosphorylation of neurogranin, protein kinase $C$, and $\mathrm{Ca} 2+/$ calmodulin dependent protein kinase II in opioid tolerance and dependence. Neurosci. Lett. 404, 266-269.

Steiner, R. C., Heath, C. J., and Picciotto, M. R. (2007). Nicotineinduced phosphorylation of ERK in mouse primary cortical neurons: evidence for involvement of glutamatergic signaling and CaMKII. J. Neurochem. 103, 666-678.

Talebizadeh, Z., Butler, M. G., and Theodoro, M. F. (2008). Feasibility and relevance of examining lymphoblastoid cell lines to study role of microRNAs in autism. Autism Res. 1, 240-250.

Tao, P. L., Law, P. Y., and Loh, H. H. (1987). Decrease in delta and mu opioid receptor binding capacity in rat brain after chronic etorphine treatment. J. Pharmacol. Exp. Ther. 240, 809-816.

Urban, J. D., Clarke, W. P., Von Zastrow, M., Nichols, D. E., Kobilka, B., Weinstein, H., Javitch, J. A., Roth, B. L., Christopoulos, A., Sexton, P. M., Miller, K. J., Spedding, M., and Mailman, R. B. (2007). Functional selectivity and classical concepts of quantitative pharmacology. J. Pharmacol. Exp. Ther. 320, 1-13.

Vaillant, A. R., Zanassi, P., Walsh, G. S., Aumont, A., Alonso, A., and Miller, F. D. (2002). Signaling mechanisms underlying reversible, activity-dependent dendrite formation. Neuron 34, 985-998.

Valjent, E., Corbille, A. G., BertranGonzalez, J., Herve, D., and Girault, J. A. (2006). Inhibition of ERK pathway or protein synthesis during reexposure to drugs of abuse erases previously learned place preference. Proc. Natl. Acad. Sci. U.S.A. 103, 2932-2937.

Valjent, E., Pages, C., Herve, D., Girault, J. A., and Caboche, J. (2004). Addictive and non-addictive drugs induce distinct and specific patterns of ERK activation in mouse brain. Eur. J. Neurosci. 19, 1826-1836.

Violin, J. D., and Lefkowitz, R. J. (2007). Beta-arrestin-biased ligands at seven-transmembrane receptors. Trends Pharmacol. Sci. 28, 416-422.

von Bohlen Und Halbach, O. (2007). Immunohistological markers for staging neurogenesis in adult hippocampus. Cell Tissue Res. 329, 409-420.

Wang, K. C., and Chang, H. Y. (2011). Molecular mechanisms of long noncoding RNAs. Mol. Cell 43, 904-914.

Wu, Q., Law, P. Y., Wei, L. N., and Loh, H. H. (2008). Post-transcriptional regulation of mouse mu opioid receptor (MOR1) via its $3^{\prime}$ untranslated region: a role for micro-RNA23b. FASEB J. 22, 4085-4095.

Wu, Q., Zhang, L., Law, P. Y., Wei, L. N., and Loh, H. H. (2009). Longterm morphine treatment decreases the association of mu-opioid receptor (MOR1) mRNA with polysomes through miRNA23b. Mol. Pharmacol. 75, 744-750.

Yuan, B., Dong, R., Shi, D., Zhou, Y., Zhao, Y., Miao, M., and Jiao, B. (2011). Down-regulation of miR23b may contribute to activation of the TGF-beta1/Smad3 signalling pathway during the termination stage of liver regeneration. FEBS Lett. 585, 927-934.

Zeng, Y. (2006). Principles of micro-RNA production and maturation. Oncogene 25, 6156-6162.
Zeng, Y., and Cullen, B. R. (2003). Sequence requirements for micro-RNA processing and function in human cells. RNA 9, 112-123.

Zhang, J., Ferguson, S. S., Barak, L. S., Bodduluri, S. R., Laporte, S. A., Law, P. Y., and Caron, M. G. (1998). Role for $G$ protein-coupled receptor kinase in agonist-specific regulation of mu-opioid receptor responsiveness. Proc. Natl. Acad. Sci. U.S.A. 95, 7157-7162.

Zhang, Z. W., Zhang, L. Q., Ding, L., Wang, F., Sun, Y. J., An, Y., Zhao, Y., Li, Y. H., and Teng, C. B. (2011). MicroRNA-19b down regulates insulin 1 through targeting transcription factor NeuroD1. FEBS Lett. 585, 2592-2598.

Zheng, H., Chu, J., Zeng, Y., Loh, H. H., and Law, P. Y. (2010a). Yin Yang 1 phosphorylation contributes to the differential effects of mu-opioid receptor agonists on microRNA190 expression. J. Biol. Chem. 285 21994-22002.

Zheng, H., Loh, H. H., and Law, P. Y. (2010b). Agonist-selective signaling of $\mathrm{G}$ protein-coupled receptor: mechanisms and implications. IUBMB Life 62, 112-119.

Zheng, H., Zeng, Y., Chu, J., Kam, A. Y., Loh, H. H., and Law, P. Y. (2010c). Modulations of NeuroD activity contribute to the differential effects of morphine and fentanyl on dendritic spine stability. J. Neurosci. 30, 8102-8110.

Zheng, H., Zeng, Y., Zhang, X., Chu, J., Loh, H. H., and Law, P. Y. (2010d). \{Micro\}-opioid receptor agonists differentially regulate the expression of miR-190 and NeuroD. Mol. Pharmacol. 77, 102-109.

Zheng, H., Chu, J., Zhang, Y., Loh, H. H., and Law, P. Y. (2011).
Modulating micro-opioid receptor phosphorylation switches agonistdependent signaling as reflected in PKCepsilon activation and dendritic spine stability. J. Biol. Chem. 286, 12724-12733.

Zheng, H., Loh, H. H., and Law, P. Y. (2008). \{Beta\}-arrestin-dependent \{micro\}-opioid receptor-activated extracellular signal-regulated kinases (ERKs) Translocate to Nucleus in Contrast to G proteindependent ERK activation. Mol. Pharmacol. 73, 178-190.

Zuo, Z. (2005). The role of opioid receptor internalization and betaarrestins in the development of opioid tolerance. Anesth. Analg. 101, 728-734.

Conflict of Interest Statement: The authors declare that the research was conducted in the absence of any commercial or financial relationships that could be construed as a potential conflict of interest.

Received: 09 February 2012; accepted: 30 May 2012; published online: 15 June 2012.

Citation: Zheng H, Law P-Y and Loh $H H$ (2012) Non-coding RNAs regulating morphine function: with emphasis on the in vivo and in vitro functions of miR-190. Front. Gene. 3:113. doi: 10.3389/fgene.2012.00113

This article was submitted to Frontiers in Non-Coding RNA, a specialty of Frontiers in Genetics.

Copyright (C) 2012 Zheng, Law and Loh. This is an open-access article distributed under the terms of the Creative Commons Attribution Non Commercial License, which permits non-commercial use, distribution, and reproduction in other forums, provided the original authors and source are credited. 